\title{
A PLEA FOR THE INVESTIGATION OF THE CONDI TIONS AFFECTING THE LENGTH OF TRADE LIFE
}

\author{
By Robert Hunter, Esq., \\ Of New York City.
}

When I was asked to speak on the subject given me I accepted with pleasure, but as I thought more about it and began to read the literature on the subject I became convinced that I knew very little about the subject, and also that very little of value upon it has been written in this country. Accidents connected with the mines and the railroads and the effects of certain diseases have been studied in their relation to the trade life. We know something of tuberculosis by reason of the fact that commissions have been at work upon that subject. In a few trades, such as cigarmaking, and working with glass, a certain amount of information of very great value has been gathered. I doubt very much, however, whether there can be a great deal said of importance upon the general subject. The literature is certainly very scant and the facts are so few that they make a poor comparison with studies abroad in the same field.

The most important thing I can do to-day is to make an earnest appeal, which shall stand in the proceedings of this conference, for a national commission to study this subject. It is even more important than the study of tuberculosis; it is as important as the work of the National Child Labor Committee. There are many things that enter into a serious consideration of the trade life. It brings up in toto the sanitary conditions throughout the large industrial districts. It involves the child labor, the tuberculosis, and the housing problems, not to speak of the many other problems resulting directly from our present-day factory system. We would all agree that we have progressed far into a very complicated and intricate system of industry which we call the capitalist system, or as it is more generally known, the factory system. To know how that factory system affects the workers, that is, affects their length of life, $(500)$ 
their physical and their mental condition, would indeed seem to be one of the most important national topics that could engage the attention of such an academy as this or of such an official organization as the national Bureau of Labor. The facts now known are hardly worthy of serious discussion. I say this as a result of my studies as well as of my observation. I feel that we now have no conception whatever of the influence which specific kinds of work have upon the physical and mental condition, as well as upon the length of the trade life of certain classes of workmen, who are engaged in certain large industries of this country. I have just been reading "The Jungle," that very remarkable book of Upton Sinclair. I was impressed while I worked in that great district, the Chicago stockyards, with what seemed to me to be the almost indescribable unsanitary conditions, with the mental atmosphere of the place, with the driving, with the intensity of the work, with the anguish involved in the low wages, the irregular hours and the constant fear and dread of want among the people there. But although I am pretty well acquainted with that district in Chicago, I am persuaded that I have never fully understood the destructive influence of the stock yards upon the physical, mental and moral conditon of the people there. It is just such conditons as are to be found there which convince me that if we could really have a study of the factory conditons in any such locality and of their effect upon the life and health of the community, we should have an epoch-making social study.

But even more than any study of any particular section or any particular industry I should wish that we might now have some group of men studying generally the effect of the factory conditions of this country upon the lives and welfare of the working people. For instance, we ought to know first the occupations injurious to health. Such occupations have been well classified by Dr. J. T. Arlidge, in his valuable study of "The Hygiene, Diseases, and Mortality of Occupations," as follows:

Occupations injurious to health by (I) the generation of dust; (2) the employment of materials of distinctly poisonous or highly noxious nature; $(3)$ the evolution of vapors of poisonous or injurious properties; (4) the action of excessive temperatures; (5) the action of electricity; (6) abnormal atmospheric pressure; (7) ex- 
cessive use, friction or strain of the body or of special organs or parts; (8) exposure to infectious, contagious or parasitic diseases. These classes cover all dangerous occupations. A thorough study of industry on these lines would show in the most complete way the dangers incident to the battlefield of toil. The length of the trade life in each industry could be averaged, and most important of all, the risks of various trades or occupations could be set down with some accuracy. To my mind this work is worthy of the most earnest thought of this Academy, and I could wish that it might take some steps to bring it to the attention of the President of the United States, who is becoming interested in certain very similar lines of inquiry. Knowing my interest and my work concerning the work of women and child labor reform as well as in the tuberculosis movement, you will not think me unappreciative of these other movements when I urge this as a necessity of equal importance.

I say this because I am convinced that we are cruelly and foolishly wasteful of human life in this country. James J. Hill has recently said that we are wasting the natural resources of our country in a most inexcusable way. I wish to say that we are wasting and degrading human life in this country in a way which will inevitably bring the direst consequences. The cotton mills of the South are destroying childhood as effectually as if cannibalism reigned in that section of the country. The railroads are killing and injuring its employees in a way which may almost be called murder. The exhausting pace set here, and the intensity of our present-day work for all classes of laborers must affect the working life of the community fundamentally. All these subjects are worthy of serious study by our National Government, because they have to do with the efficiency of labor, and our national greatness is more a result of a superior and highly efficient working class than of any other cause whatsoever. But we cannot exploit it wastefully or ignore conditions which impair its efficiency without as a nation paying the penalty. For, after all, in the words of Lincoln, "capital is only the fruit of labor, and could never have existed if labor had not first existed."

I am sure it is known to all of you that many people in Great Britain believe that the factory system there has caused widespread degeneracy among workingmen. There is a variety of reasons (502) 
given for this; among others, they believe child labor, poor food, overwork, poverty and bad sanitary conditions are responsible largely for this widespread physical degeneration or physical deterioration. Whatever the causes, a serious type of deterioration is reasonably certain. Now it would be most important for us to forsee such a result if it is likely to occur in this country, for by such foresight we would perhaps be able to prevent happening to us a result so deplorable. Nothing could be of greater importance than to know that our industrial population is not growing stronger and healthier. If it is actually deteriorating in the length of the working life, in physical stature, in general physical conditon, or by disease, then it is of vital importance that we know these facts also. For if it be true that the industrial population of this country is degenerating, then that is a kind of race suicide which cannot be spoken of jestingly. It will finally strike at the very foundation of our present industrial and economic institutions. For these reasons I could wish that we were to have together with the investigations now to be undertaken into women's and children's labor a very careful investigation into the physical condition of our entire working population. My own feeling is that the physical condition of the workers is not deteriorating, but I am convinced sometimes that the conditions in this country which we look upon with so much optimism are by no means realized by us. Indeed, they seem to me at times infinitely worse than any of us are likely or willing to believe.

It is important to use such an opportunity as the present Annual Meeting of the Academy to present the great need of more accurate and more extensive information. The first thing necessary is in some way to acquire some actual facts. When we know the facts, when we realize the conditions in these industries, it will be time to urge upon the community such reforms and such remedial measures as may seem to be necessary. 